\title{
Healing of snow surface-to-surface contacts by isothermal sintering
}

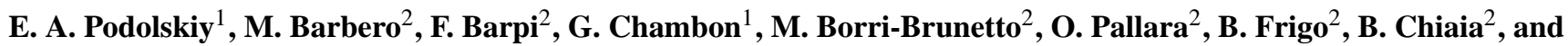 \\ M. Naaim ${ }^{1}$ \\ ${ }^{1}$ IRSTEA (UR ETGR) - Centre de Grenoble, 2 rue de la Papeterie, BP 76, 38402 St.-Martin-d'Hères CEDEX, France \\ ${ }^{2}$ Department of Structural, Building and Geotechnical Engineering, Politecnico di Torino, Corso Duca degli Abruzzi 24, \\ 10129, Turin, Italy
}

Correspondence to: E. A. Podolskiy (evgeniy.podolskiy@gmail.com)

Received: 3 April 2014 - Published in The Cryosphere Discuss.: 13 May 2014

Revised: 9 July 2014 - Accepted: 3 August 2014 - Published: 9 September 2014

\begin{abstract}
Natural sintering in ice is a fundamental process determining mechanical properties of various ice forms. According to the literature, limited data are available about the complex subjects of snow sintering and bond formation. Here, through cold laboratory mechanical tests with a new shear apparatus we demonstrate time-dependent effects of isothermal sintering on interface strengthening at various normal pressures. Measurements showed that interfacial strength evolved rapidly, conforming to a power law (mean exponent $\approx 0.21$ ); higher pressure corresponded to higher initial strength and sintering rates. Our findings are consistent with observations on homogeneous snow, provide unique records essential for slope stability models and indicate the significant importance of normal load on data interpretation.
\end{abstract}

\section{Introduction}

Due to a high homologous temperature, snow and ice sintering (i.e. grain bonding leading to improved strength) has the fastest rate of any other Earth material at similar pressures and temperatures (Szabo and Schneebeli, 2007; Gubler, 1982). Owing to this, sintering plays a crucial role in the mechanical behaviour of snow (Gubler, 1978) and snow avalanche release (McClung, 1979; Schweizer, 1999). Postfracture healing of weak snowpack layers, which are a prerequisite for slab avalanche initiation, can have an important influence on the critical length of macroscopic cracks (McClung, 2011). For such basal cracks, Louchet et al. (2002) suggested that healing may significantly reduce stress concentrations at the crack tip and thus be equivalent to an apparent increase of the shear toughness. Strength recovery in- duced by sintering was also suggested as a stabilizing factor in the case of stress relaxation occurring after rupture without avalanche triggering (Fyffe and Zaiser, 2004). Furthermore, through a snow creep instability approach, based on a kinematic balance between ice bond rupture and rewelding, Louchet (2001) showed that healing rates of damaged snow are crucial in determining the onset of slab instability. At smaller scales, using a fibre bundle model Reiweger et al. (2009) demonstrated that the competing effects of bond breaking and rewelding between two plates are sufficient to explain the strain-rate-dependent behaviour of snow.

It is known that there are at least six mass-transport mechanisms playing a role in the growth of ice bonds (Maeno and Ebinuma, 1983) and many factors that may affect sintering: temperature and its gradient, normal pressure, microstructural properties of grains, and pore-space configuration/geometry (McClung and Schaerer, 2006; Blackford, 2007). Isothermal snow sintering is mainly controlled by vapour diffusion (Hobbs and Mason, 1964), while external pressure intensifies the process through plastic deformation and recrystallization (Blackford, 2007). Experimentally and theoretically it was shown that the bond-to-grain ratio and strength change with time according to a power law on samples of ice spheres and homogeneous snow (Hobbs and Mason, 1964; Mellor, 1975; Colbeck, 1997; van Herwijnen and Miller, 2013).

Even though in the last five decades a large number of studies have addressed sintering rates of ice as a fundamental process (Blackford, 2007), experimental data on sintering of snow weak layers or cracks has remained elusive and primarily qualitative (Fyffe and Zaiser, 2004; Birkeland et al., 2006). Quantitatively it is unknown whether existing knowledge on homogeneous snow may be directly 
incorporated into models simulating cracks and weak layers. To our knowledge, Birkeland et al. (2006) and Reiweger (2011) provided the first in situ and experimental evidence of post-fracture healing of weak layers. However, those measurements could not be put to any operational or practical use due to missing details that are most crucial for sintering (like temperature, normal pressure, grain size or healing time, Blackford, 2007). The influences of these parameters were to some extent investigated for homogeneous snow (e.g. Ramseier and Sander, 1966; de Montmollin, 1982; Matsushita et al., 2012; van Herwijnen and Miller, 2013) and for interfaces, but without a focus on sintering as a function of time (Casassa et al., 1991). Hence, the healing dependence on normal pressure remains unknown, and some authors have indicated the need to collect more records about weak-layer and homogeneous snow sintering (e.g. Birkeland et al., 2006; van Herwijnen and Miller, 2013). Furthermore, in more general terms, regarding bond formation, McClung and Schaerer (2006) noted "the extremely limited results available about this complex and important subject".

Here, we address these issues by focusing on sintering of planar snow interfaces with time, under constant temperature and at various normal pressures. For a given snow sample, the newly created internal interface (which is a simple analogue for a fractured weak layer or crack) corresponds to an excess surface energy that is greater than the bulk energy. Accordingly, the grain contact area of the new interface evolves toward thermodynamic equilibrium with the snow blocks above and below it. This process is manifested through an evolution of the global strength of the interface, which we have attempted to measure for different loading conditions. Indeed, consideration of the newly created snow interface as a model of a healing snow crack is a rough firstorder approximation (for examples of possible complexity see Heierli et al., 2008). Nevertheless, due to the complete absence of any alternative methods to measure the process, we view the method described in this paper as a simple mean to address this poorly understood issue.

After providing details of the instrument and the experimental procedure, we show and discuss the results of the tests, focused specifically on interfacial strength evolution with time under controlled laboratory conditions, and compare with previous studies where possible.

\section{Materials and methods}

The experiments were conducted in a cold laboratory (CEN, St.-Martin-d'Hères, France), where the temperature was kept at $-9.0 \pm 0.6{ }^{\circ} \mathrm{C}$ and the relative humidity was $\approx 70 \%$. For the mechanical tests, we used a portable force-controlled apparatus with adjustable shear-loading rate and normal pressure for snow specimen dimensions $160 \mathrm{~mm} \times 160 \mathrm{~mm} \times$ $80.8 \mathrm{~mm}$ (length $\times$ width $\times$ height) (Fig. 1). Ultimately, this instrument (with a weight of about $7 \mathrm{~kg}$ ) is being developed
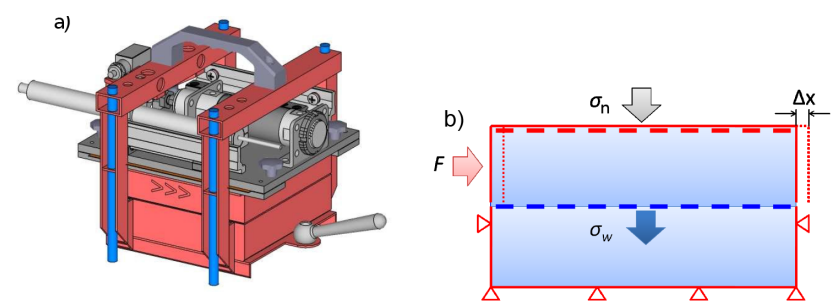

c)

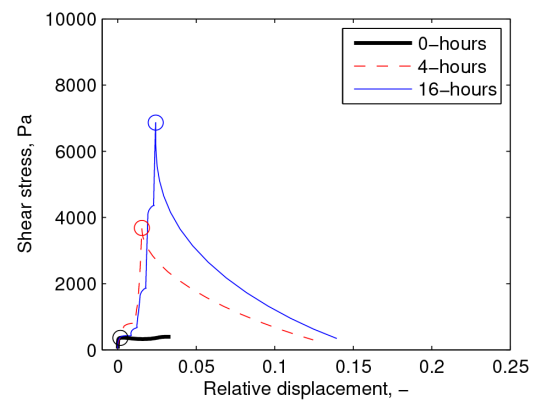

Figure 1. (a) Schematic illustration of the apparatus and (b) of the inner part of the apparatus with a snow specimen inside (see text for details); (c) stress-relative displacement curves showing examples of failure stress (shown by circles) increase after 0,4 and $16 \mathrm{~h}$ of sintering $\left(\sigma_{\mathrm{n}}=0\right)$.

for in situ measurements of the mechanical properties of weak snow layers in avalanche release zones (Barbero et al., 2013). (Results of laboratory and in situ tests with artificial and natural weak layers will be published elsewhere.)

Loading of samples was produced as follows: highpressure air from an air compressor transmitted a horizontal load to the upper part of the shear box through a pneumatic cylinder (Fig. 1a and b). Constant normal pressure, $\sigma_{\mathrm{n}}$, was induced through inflation of a rubber membrane (within about $1 \mathrm{~s}$ ) in the upper part of the shear box (Fig. 1b). Shear displacements, normal pressures and shear force $(F)$ were recorded for each test with high-frequency gauges (see Supplement for details; Table 1) at $200 \mathrm{~Hz}$ sampling rate. The shear stress exerted on the tested snow interfaces is defined as $\tau=F / A$, where $A$ is $256 \mathrm{~cm}^{2}$.

Several homogeneous snow blocks, comprised of fine grained snow (density $230-400 \mathrm{~kg} \mathrm{~m}^{-3}$ ), were harvested from two sites in the French Alps (Col du Lautaret 2000 m a.s.l., Massif du Connex - 1200 m a.s.l.) and from St.-Martin-d'Hères (near the laboratory), transported in thermo-insulated boxes, and stored in a cold storage room at $-20^{\circ} \mathrm{C}$ for 10 to 100 days. Sample properties are provided in Table 2. Natural snow blocks were collected from flat open spaces and considered homogeneous based on standard snow-pit observations. Even in cold laboratory conditions the difficulty in creating truly homogeneous snow samples is known (van Herwijnen and Miller, 2013). Micro-scale heterogeneities are unavoidable in natural and artificial snow samples and are inherent in snow as a material. 
Table 1. Description of sensors.

\begin{tabular}{lll}
\hline Sensor & Producer, model & $\begin{array}{l}\text { Linearity error (\% f.s.)/ } \\
\text { accuracy in absolute values }\end{array}$ \\
\hline Displacement transducer & RDP, linear variable differential transformer DCW1000B & $0.1 \% / \pm 0.025 \mathrm{~mm}$ \\
Force transducer & Hottinger Baldwin Messtechnik, C2 & $0.2 \% / \pm 1 \mathrm{~N}$ \\
Pressure sensing platform & General Electric Company, UNIK 5000 & $0.2 \% / \pm 1 \mathrm{~Pa}$ \\
\hline
\end{tabular}

Table 2. Physical properties of tested snow samples. Snow properties are characterized according to Fierz et al. (2009). Errors correspond to standard deviations between measurements.

\begin{tabular}{|c|c|c|c|c|c|c|}
\hline $\begin{array}{l}\text { Snow block } \\
\text { number/number of } \\
\text { samples } \\
\text { used/harvested at } \\
\text { lat., long. }\end{array}$ & $\begin{array}{l}\text { Storage time } \\
\text { in cold room } \\
\text { at }-20^{\circ} \mathrm{C} \\
\text { before tests } \\
\text { (days) }\end{array}$ & $\begin{array}{l}\text { Density } \\
\left(\mathrm{kg} \mathrm{m}^{-3}\right)\end{array}$ & Snow type & $\begin{array}{l}\text { Hand hardness } \\
\text { index/shear vane } \\
\text { resistance }(\mathrm{kPa})\end{array}$ & $\begin{array}{l}\text { SSA } \\
\left(\mathrm{m}^{2} \mathrm{~kg}^{-1}\right)\end{array}$ & $\begin{array}{l}\text { Optical grain } \\
\text { diameter } \\
(\mathrm{mm})\end{array}$ \\
\hline $\begin{array}{l}\# 4 / 1 / 45.199^{\circ} \mathrm{N}, \\
5.772^{\circ} \mathrm{E}\end{array}$ & 10,69 & $270 \pm 38$ & $\begin{array}{l}\text { DFdc, decomposed } \\
\text { precipitation parti- } \\
\text { cles (were close to } \\
0^{\circ} \mathrm{C} \text { during } \\
\text { harvesting) }\end{array}$ & Knife/20.0 \pm 5.0 & $17.7 \pm 0.8$ & $0.37 \pm 0.02$ \\
\hline $\begin{array}{l}\# 3 \mathrm{a} / 3 / 45.038^{\circ} \mathrm{N}, \\
6.399^{\circ} \mathrm{E}\end{array}$ & 34,69 & $369 \pm 5$ & $\begin{array}{l}\text { RGlr, } \\
\text { cohesive old snow }\end{array}$ & $\mathrm{Knife} / 24.8 \pm 0.9$ & $14.6 \pm 0.4$ & $0.45 \pm 0.01$ \\
\hline $\begin{array}{l}\# 3 \mathrm{~b} / 10 / 45.038^{\circ} \mathrm{N}, \\
6.399^{\circ} \mathrm{E}\end{array}$ & 104 & $397 \pm 11$ & $\begin{array}{l}\text { RGlr, } \\
\text { cohesive old snow }\end{array}$ & Knife/23.3 \pm 5.3 & $18.4 \pm 1.7$ & $0.36 \pm 0.03$ \\
\hline $\begin{array}{l}\# 1 / 10 / 45.015^{\circ} \mathrm{N}, \\
5.743^{\circ} \mathrm{E}\end{array}$ & 79 & $234 \pm 15$ & $\begin{array}{l}\text { DFbk, wind } \\
\text { packed snow }\end{array}$ & Pencil/2.95 \pm 0.7 & $28.0 \pm 1.4$ & $0.23 \pm 0.01$ \\
\hline
\end{tabular}

The snow blocks were then cut into rectangular prisms using a saw or specially constructed blades. The snow prisms, which we call specimens, were installed in the shear cell and split horizontally in the middle using a thin blade or wire $(<0.5 \mathrm{~mm})$. Then the specimens were immediately (i.e. effectively cutting the sintering time to about $30 \mathrm{~s}-1 \mathrm{~min}$ ) subjected to horizontal loading (i.e. shearing) at a constant rate of about $0.7 \mathrm{kPa} \mathrm{s}^{-1}$. Subsequently, the specimens were reassembled and left to sinter for 4,16 or $23 \mathrm{~h}$ and re-tested. The limitations of the described procedure will be shown to be negligible for the relatively long timescales of our interest, but indeed not in view of the rapid sintering times (see Sect. 4 for details).

Normal pressure in the experiments was produced in two different ways: (1) during shearing - by the instrument through the previously mentioned inflation of the membrane (hereafter $\sigma_{\mathrm{n}}$ ); and (2) before shearing - by loading samples with weights for all period of sintering (hereafter $\sigma_{\mathrm{c}}$ ). The tests were repeated at three different instrumental normal pressures, $\sigma_{\mathrm{n}}$ : due to weight of snow only, $(0.11 \pm 0.03 \mathrm{kPa})$, and with an additional external pressure of 0.5 or $1.0 \mathrm{kPa}$. Such pressures were equivalent to 20 or $40 \mathrm{~cm}$ of snow with density $250 \mathrm{~kg} \mathrm{~m}^{-3}$, respectively. Some of the specimens were also left to sinter under a constant normal load, $\sigma_{\mathrm{c}}$ $(0.5 \mathrm{kPa}$ using weights) for 4 or $16 \mathrm{~h}$, in order to investigate the effects of permanent load on sintering. These samples were sheared with $\sigma_{\mathrm{n}}=0.5$ or $1.0 \mathrm{kPa}$, i.e. $\sigma_{\mathrm{n}} \geq \sigma_{\mathrm{c}}$. In total we tested 24 specimens at various conditions resulting in 91 successful individual tests (see Table S1 in the Supplement).

\section{Results}

The observed time to failure was within $9 \mathrm{~s}$ in $90 \%$ of the tests (the median time to failure was $3 \mathrm{~s}$ ). The relative horizontal displacement at failure was between 0.2 and $14.2 \%$ depending mainly on snow density but also on sintering time (the median value was $2 \%$ ). The horizontal deformation rates were higher than $10^{-1} \mathrm{~s}^{-1}$. Due to the design of the instrument the crack occurred at the interface in all considered tests (as intended). The effect of time on strength can be seen in Fig. 1c. A clear peak stress, marked by circles, is observed for tests conducted after 4 or $16 \mathrm{~h}$, while less pronounced peaks occur for tests made immediately after the cut. The shear strength of interfaces, $\tau_{\mathrm{f}}$, corresponds to the peak stress. From Fig. 1c it is evident that longer sintering times are associated with higher $\tau_{f}$ and displacements at failure. Note that the load-controlled mode and the present geometry of the instrument do not allow any direct insights into the residual friction (e.g. Casassa et al., 1991). Nevertheless, through supplementary high-speed photography of multiple tests it was confirmed that peak stresses always correspond to initiation 

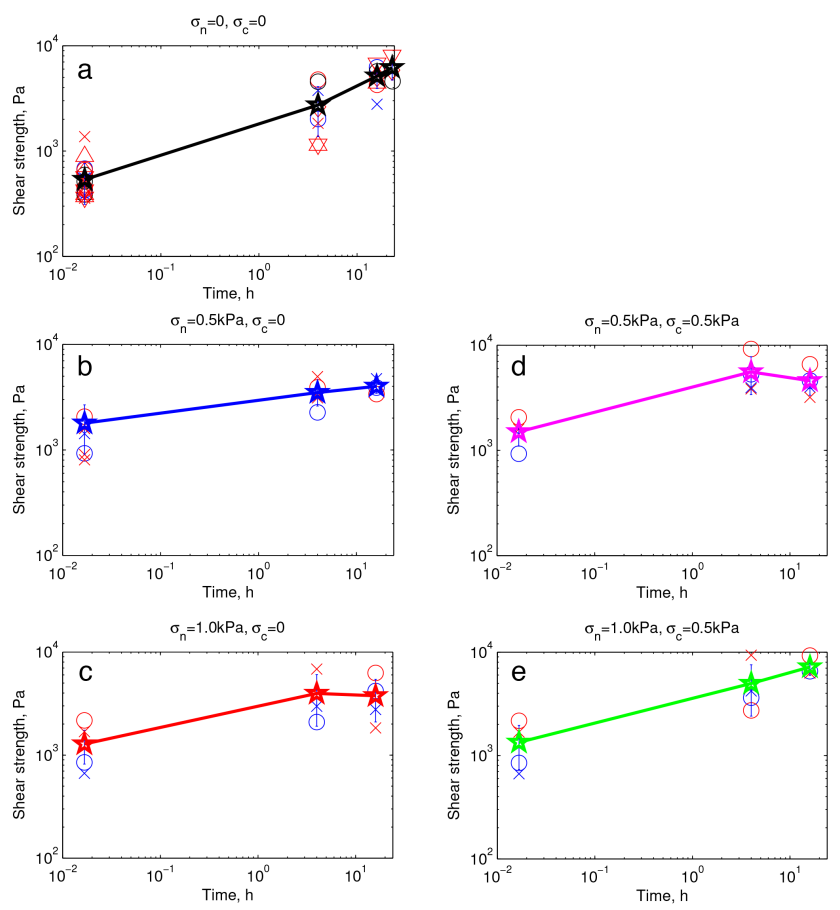

Figure 2. Shear strength evolution with sintering time for all samples and all loading conditions (means are indicated by stars and connected by lines; error bars show standard deviations for available measurements: different marker shapes correspond to different specimens; samples of the same snow type have the same colour). (a) Baseline tests with no external normal pressure, and no preloading $\left(\sigma_{\mathrm{n}, \mathrm{c}}=0\right)$; (b) and (c) with $\sigma_{\mathrm{n}}=0.5$ or $1.0 \mathrm{kPa}$, respectively; $\sigma_{\mathrm{c}}=0$. (d) and (e) with $\sigma_{\mathrm{n}}=0.5$ or $1.0 \mathrm{kPa}$, respectively and $\sigma_{\mathrm{c}}=0.5 \mathrm{kPa}$.

of catastrophic failure of specimens (not shown; to be published elsewhere).

The results of all experiments are shown in Fig. 2 in terms of calculated shear strength vs. healing time. The temporal evolution of the mean strengths for the different loading conditions is summarized in Fig. 3. In general, the strength increased with time for all loading conditions (Figs. 1c and 2). Two slightly decreasing trends (between 4 and $16 \mathrm{~h}$ ) observed in Fig. $2 \mathrm{c}$ and d may be due to some artifact (e.g. improper crack-face placement or partial breakage of some bonds during sample preparation). In order to verify that such values do not affect the results, we filtered all measurements by removing all tests giving lower values for higher times. The mean values of this selected population of tests are indicated in Fig. 3 as dashed lines.

Tests performed without any external normal pressure $\left(\sigma_{\mathrm{n}}\right)$ or permanent load by weights $\left(\sigma_{\mathrm{c}}\right)$ hereafter considered as baseline values, $\tau_{\mathrm{f}_{-} \mathrm{b}}$, showed an increase in failure strength from an average of $0.5 \pm 0.2 \mathrm{kPa}$ to $5.1 \pm 1.2$ and $6.2 \pm 1.4 \mathrm{kPa}$ after 16 and $23 \mathrm{~h}$, respectively (Fig. 2a).

With the additional external pressures, $\sigma_{\mathrm{n}}$, the strength increased compared to $\tau_{\mathrm{f}_{-} \mathrm{b}}$ for 0 and $4 \mathrm{~h}$ measurements (Fig. $2 \mathrm{~b}$

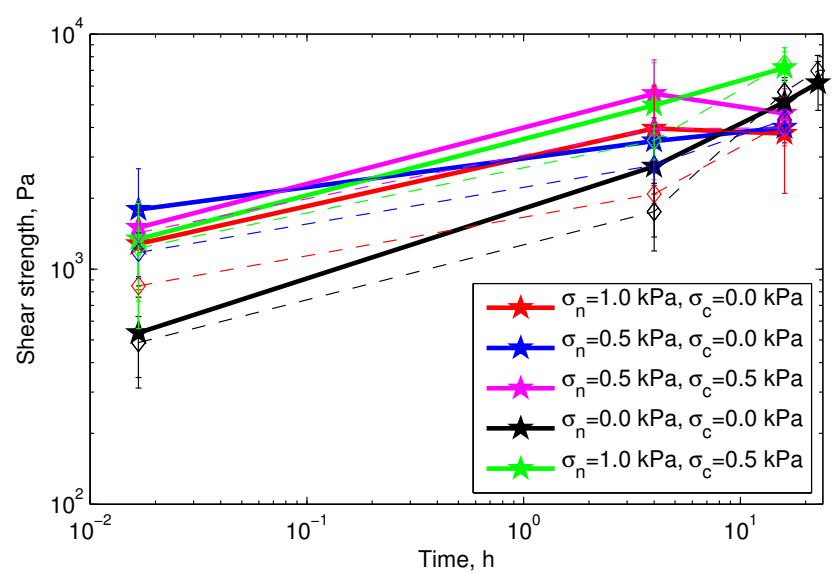

Figure 3. Mean shear strength evolution with sintering time for each set of loading conditions (thick lines indicate all tests; dashed lines - filtered tests).

and c), on average by a factor of 1.8. However, the increase in strength was comparable for both $\sigma_{\mathrm{n}}=0.5$ and $1.0 \mathrm{kPa}$. Specimens which were loaded with $\sigma_{\mathrm{c}}=0.5 \mathrm{kPa}$ for 4 and $16 \mathrm{~h}$ before testing (Fig. $2 \mathrm{~d}$ and e) show strengthening curves which are similar to those without any permanent loading $\left(\sigma_{\mathrm{c}}=0 \mathrm{kPa}\right)$. For example, compared with $\tau_{\mathrm{f} \_\mathrm{b}}$ there is a more than twofold strength increase of 0 and $4 \mathrm{~h}$ values (some further discussion of possible differences is given below).

\section{Discussion}

\subsection{Strengthening rates}

Previous published interfacial strengthening rate measurements and estimates (i.e. values assumed for modelling) vary greatly and are extremely scarce. For example, in situ observations on strengthening of post-collapse layers were reported as linear coefficients and ranged from 0.07 to $0.3 \mathrm{kPah}^{-1}$ (Birkeland et al., 2006). Some modelling studies used a typical $10 \mathrm{~s}$ timescale (with sensitivity tests within a range $1 \mathrm{~s}-28 \mathrm{~h}$ ) for the recovery of weak-layer strength to its original value (Fyffe and Zaiser, 2004). The average rate of strengthening within $16 \mathrm{~h}$ calculated for global strength means of all results, $0.26 \pm 0.09 \mathrm{kPa} \mathrm{h}^{-1}$, was comparable to the values reported by Birkeland et al. (2006). However, constant rates are unlikely to apply, because even with high variability between tests, the data demonstrate that the most rapid healing occurs within the first four hours, and after that slows down and continues at lower rates (Fig. 3). Comparison to other experimental results, for example, obtained for artificial homogeneous snow by Matsushita et al. (2012) (0.08$0.17 \mathrm{kPah}^{-1}$ ) and for unfractured weak layers by Jamieson and Johnston (1999) (about $8 \mathrm{Pah}^{-1}$ ), is not straightforward due to other effects in their data (such as different timescales, 


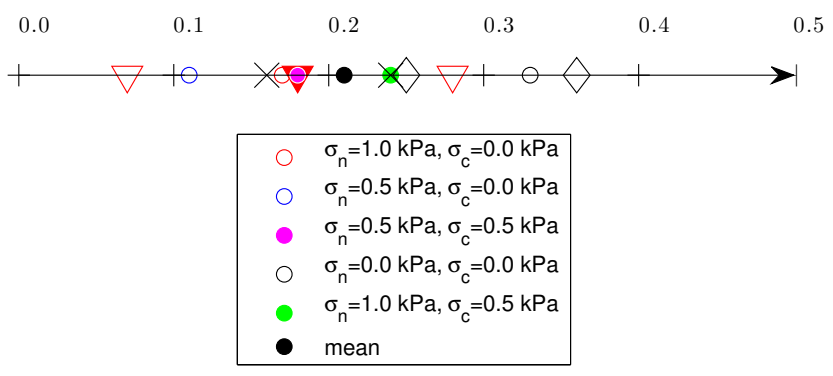

Figure 4. Exponent $b$ of the power law fit at each set of loading conditions $\left(\tau_{\mathrm{f}}\right)$ compared to other studies $(\times-$ Hobbs and Mason, 1964; $\diamond-$ Blackford, 2007; $\nabla$ - van Herwijnen and Miller, 2013, where empty triangles - marginal values, $\boldsymbol{\nabla}-$ the mean).

densification, different microstructure including grain shape, bond spacing, etc.).

In line with previous studies on homogeneous snow (Hobbs and Mason, 1964), analysis of data shown in Fig. 3 suggests that a power law function $f(t)=a t^{b}$ for $\tau_{\mathrm{f}}(t)$ fits the observed strengthening process at any conditions under consideration (with $R^{2}$ from 0.91 to 0.97 ; with two-tailed $p$ value $\leq 0.2$ for three time steps, and $\leq 0.05$ for four time steps). When we provide an empirical power law fit for the change of mean $\tau_{\mathrm{f}}$ with time in all our experiments, we obtain an exponent $0.21 \pm 0.08$ (Fig. 4). If we provide fits only for the filtered tests or exclude all measurements made at or after $16 \mathrm{~h}$ from the fitting (to avoid the previously mentioned slightly decreasing trends), we obtain similar mean results $=0.22 \pm 0.08$; if we set the first measurement time to $30 \mathrm{~s}$ instead of $1 \mathrm{~min}$, we obtain $0.19 \pm 0.08$. When we compare the results on interface strengthening with those from other studies on homogeneous snow, our $b$ values fall well within the range of previously reported values (Fig. 4).

\subsection{Influence of normal stresses}

The increase of initial interfacial strength, $\tau_{\mathrm{f}}(0)$, with normal pressure $\left(\sigma_{\mathrm{n}}\right)$ is shown in Fig. 5. The observed dispersion may be attributed to a slight uncertainty in time of the initial measurements and consequently a possible initial cohesion of the interface (see discussion below).

For evaluation of the influence of permanent normal load $\left(\sigma_{\mathrm{c}}\right)$ on sintering rates, we assume that interfacial strength is governed by the Mohr-Coulomb law (e.g. Matsushita et al., 2012) $\tau_{\mathrm{f}}(t)=c\left(t, \sigma_{\mathrm{c}}\right)+\sigma_{\mathrm{n}} \tan \phi$. Thus the failure strength of the interface depends on a constant pressure-dependent friction term and on a cohesion, $c$, evolving with time (such constitutive behaviour should be viewed with caution, since it does not provide physical phenomenological explanation and thus should be considered as a simplification). We surmise that initial strength $\tau_{\mathrm{f}}(0)$ corresponds only to the frictional part since the snow bonds did not have sufficient time to develop and may be considered as negligible. Accordingly, in order to evaluate the evolution not only of the strength but of

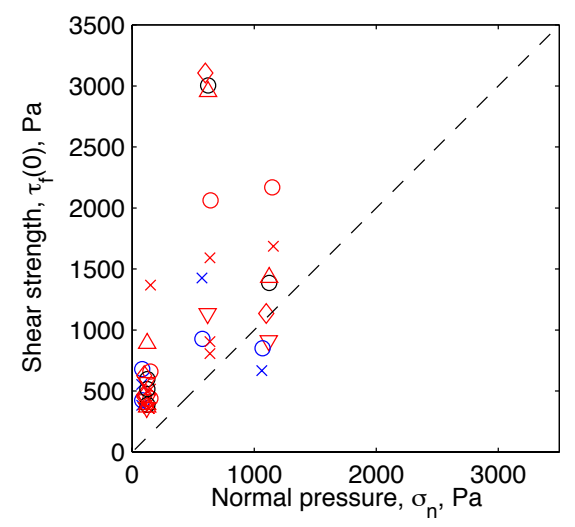

Figure 5. Influence of $\sigma_{\mathrm{n}}$ on $\tau_{\mathrm{f}}(0)$ (dashed line $-1: 1$; marker code is the same as in Fig. 2).

cohesion, without an effect of normal pressure $\left(\sigma_{\mathrm{n}}\right)$, we removed the frictional part of the strength for full and filtered tests (Fig. 6). Cohesion values suggest a possible increase of sintering rates due to long-term loading, $\sigma_{\mathrm{c}}$. Corresponding tests show an increase of cohesion of up to $70 \%$ after $4 \mathrm{~h}$ compared to tests without any permanent loading. For the $16 \mathrm{~h}$ measurements, data variability precludes a similar observation, except for one series of tests (shown in green; Fig. 6).

If the measured strength depends on $\sigma_{\mathrm{n}}$ and a temporarily evolving cohesion between grains, care should be taken in the evaluation of power law fit parameters. If the latter are estimated only for cohesion (Fig. 6), we obtain substantially different values of $a$ and $b$, which are extremely sensitive to the initial value taken for the cohesion (while not very sensitive to initial time; Fig. A1). When we assume that there is some pre-existing cohesion ( $c_{0}$ between 1 and $400 \mathrm{~Pa}$, for example), $a$ and $b$ values will vary in the range $150-3300 \mathrm{~Pa} \mathrm{~s}^{-b}$ and $0.24-1.23$, respectively (see Fig. 7 for an example).

In general, higher $c_{0}$ corresponds to lower $b$; when $c_{0}$ is $>200 \mathrm{~Pa}$, the exponents start to resemble those in the literature (Fig. A1). Interestingly, this is also in accordance with Fig. 5, where such initial cohesion values may be inferred from the data, and supports the idea, opposite to our initial assumption, that a timescale of less than $1 \mathrm{~min}$ is sufficient to have non-negligible cohesion in the experiments. Moreover, Fig. 7 suggests that the permanent load increases the scaling factor $a$, while leaving the exponent, $b$, almost unaffected. Even though only preliminary at this stage, this discussion (i) suggests that the previously shown scatter of published exponents could be caused by slight differences of normal pressure; (ii) poses strict requirements on precise pressure and time control in future tests; and (iii) indicates that we have to be careful with strength prediction at small timescales. 


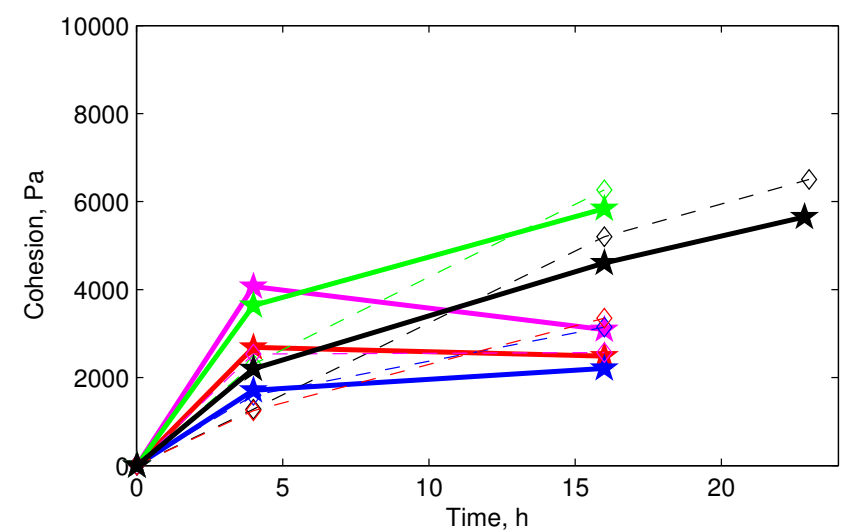

Figure 6. Cohesion evolution with sintering time (marker code is the same as in Fig. 3).

\subsection{Limitations}

The operations performed in the experiments were focused on relatively long time intervals, and not on very short timescales of sub-seconds or seconds (Gubler, 1982; Szabo and Schneebeli, 2007). Nevertheless, it was shown above that an error in the fit due to uncertainty of the initial time was negligible for the timescales of our interest. However, clearly for an extrapolation of results to smaller timescales a different methodology would be required, which is beyond the scope of the present study.

The number of time steps for which fits were made was relatively small. The optimal choice considered the very time- and labour-consuming procedures of the presented tests. Nevertheless, sensitivity tests for fits made even with only two steps (4 and $16 \mathrm{~h}$ ) indicated the stability of the obtained exponents. Furthermore, since the power law dependency was previously postulated for homogeneous snow at timescales two times smaller than in the present study (van Herwijnen and Miller, 2013), it was interesting to further extend the time range of the process.

To achieve better quantitative characterization of the normal stress effect on sintering, more experiments with larger values of normal pressure are needed.

With regard to sample splitting, the following should be noted. Similarly to common snow saw fracture tests (McClung, 2011) (where the cut is made with a saw ten times thicker than the cutting method used in the present study) the changes in microstructure caused by cutting procedure were not documented and remain unknown. It would be interesting to investigate this issue through X-ray tomography (Hagenmuller et al., 2013), which was not available in this study.

Direct projection of the results with artificially created interfaces onto real snow weak layers remains to be done. In particular, the snow densities used in this work may be limited to cracks along such types of weak layers as crusts, interfaces between two horizons of snow with different hardness, or post-collapse weak layers with negligible thickness. On

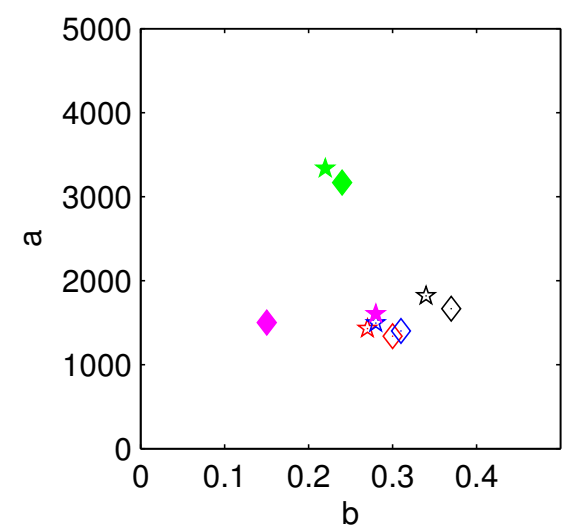

Figure 7. Example of scaling factors, $a$, and exponents, $b$, of the power law fit for the cohesion (the filtered population, where marker shapes indicate sensitivity of fit parameters for a "basis" of each fit: the first measurement is at $1 \mathrm{~min}, \diamond$, or $30 \mathrm{~s}, \star ; c_{0}=400$; see also Fig. A1).

the other hand, the experimental densities may be higher than densities of other important types of weak layers like buried surface hoar or depth hoar, thus indicating a need for further tests. Nevertheless, similarities between in situ reported rates (Birkeland et al., 2006) and results of this study, as well as recent findings about the similarity of sintering rates for sieved depth hoar and those of rounded grains (van Herwijnen and Miller, 2013), suggest that the processes responsible for bond development may be very similar.

\section{Conclusions}

The experiments showed the healing of snow interfaces, presumably through a growth of intergrain contact surfaces, leading to a fast increase of their strength. Such interface strengthening behaviour was quantitatively characterized under controlled laboratory conditions (in shear mode) for relatively long timescales through a novel instrumental technique. It was shown that normal pressure $\left(\sigma_{\mathrm{n}}\right)$ influence was associated with an increase of failure strength, and that permanent load $\left(\sigma_{\mathrm{c}}\right)$ seems to increase sintering rates. Also it was found that the interfacial strength increase is nonlinear for all reported loading conditions; it occurs most intensely within the first four hours $\left(0.71 \pm 0.22 \mathrm{kPah}^{-1}\right)$ and continues afterwards at much lower rates (e.g. within the next $12 \mathrm{~h}$ at $0.14 \pm 0.07 \mathrm{kPah}^{-1}$ ) and may be described as following a power law function of time with a mean exponent around 0.21 . This exponent agrees well with several other experimental studies, which were based on artificial homogeneous snow, completely different instrumental methods or shorter timescales (van Herwijnen and Miller, 2013). The observed dependency indicates that homogeneous and interfacial snow/ice sintering share comparable fundamental dynamics, which is very sensitive to normal pressure and indeed 
needs further investigation (e.g. through X-ray tomography). Similarly to field studies by Birkeland et al. (2006) our experiments have confirmed that newly formed interfaces, like hypothetical sub-critical weak layer cracks, are dynamic, transient phenomena. 


\section{Appendix A}

\section{A1 Additional information about tests}

Additional information is provided (i) about the sensors in Table 1, (ii) about the physical properties of tested snow samples in Table 2, (iii) about the experiments in Supplement Table S1 (please see the attached file), and finally, (iv) some sensitivity tests are shown in Fig. A1.

To complement the mechanical tests with a full documentation of snow properties, we collected the following supplementary measurements (Table 2): (1) snow density (by measuring the mass of known volumes); (2) weight of upper snow blocks (above the interface); (3) shear resistance of snow blocks (by shear-rotary vane, Domine et al., 2011); (4) specific surface area, or SSA, for estimating the optical diameter of snow grains (by dual-frequency integrating sphere for snow SSA measurement, or DUFISSS, at $1310 \mathrm{~nm}$ wave length, see Gallet et al. (2009) for details); and, finally, (5) microphotography of separated snow particles. However, we notice that differences in temporal evolution of interfacial failure strength or sintering rates based on snow properties (i.e. density, grain size or grain type) could not be evaluated due to large variability between tests, meaning that corresponding possible differences may be smaller than the variability between tests.
Furthermore, a table with an overview of performed tests is provided in Supplement Table S1 (a separate file). We note that additionally to tests described in the paper, four specimens were left to sinter for about $1653 \mathrm{~h}$ (i.e. more than two months) of sintering at $-20^{\circ} \mathrm{C}$ without any external load. These specimens had a strength of around $11.6 \pm 4.3 \mathrm{kPa}$, but since they were subjected to the lower air temperature, which could significantly slow down the growth of bonds, we did not compare them with other tests.

\section{A2 Sensitivity of power fit parameters to initial cohesion}
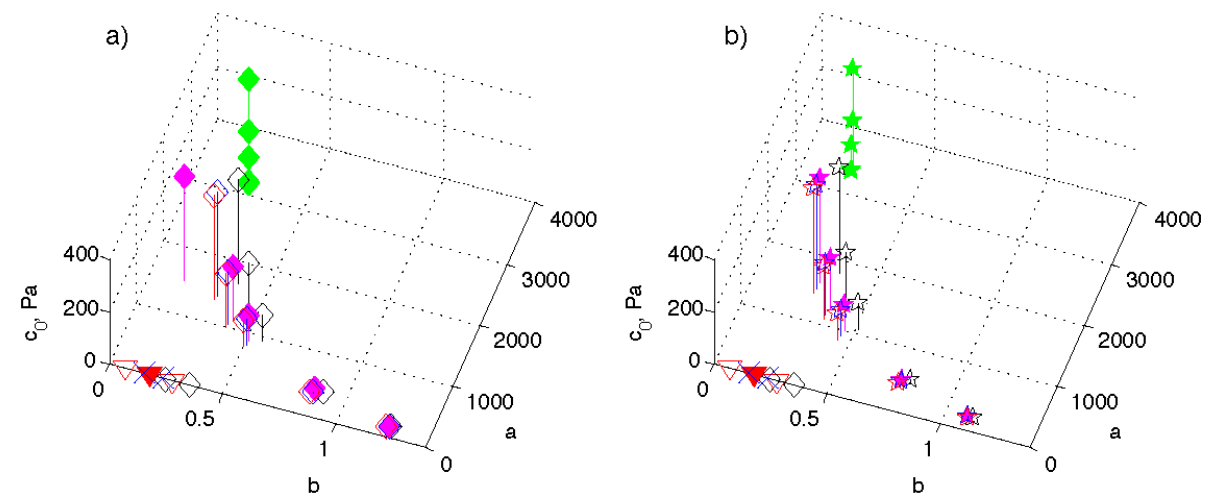

Figure A1. Sensitivity analysis of power law fit parameters $a$ and $b$ to uncertainty in $c_{0}$ for each set of loading conditions (see the main text for details; marker code is the same as in Fig. 3); (a) the filtered population of tests, where the first measurement is at 1 min, or (b) at $30 \mathrm{~s}$. For comparison $b$ axes provide exponents from other studies (marker code is the same as in Fig. 4). 


\section{The Supplement related to this article is available online at doi:10.5194/tc-8-1651-2014-supplement.}

Acknowledgements. We thank J. Roulle (for cold room operation), X. Ravanat and G. Pulfer (for help with collecting snow material), C. Carmagnola, C. Chandiou, and N. Calonne (for help with experiments), P. Hagenmuller (for discussions), and E. A. Hardwick (for improving the English in the paper). The research leading to these results was possible because of funding from the People Programme (Marie Curie Actions) of the European Union's Seventh Framework Programme (FP7/2007-2013) under REA grant agreement \#298672 (FP7-PEOPLE-2011-IIF, “TRIME”). Financial support was also provided by Project \#144, MAP 3 ("Monitoring for the Avalanche Prevision Prediction and Protection"), Obiettivo Cooperazione Territoriale Europea Italia/Francia (Alpi) 2007-2013 Alcotra. This work has also been supported by a grant from LabEx OSUG@2020 (Investissements d'avenir - ANR10 LABX56). The paper was improved thanks to the remarks of I. Reiweger and the anonymous reviewer.

Edited by: F. Dominé

\section{References}

Barbero, M., Barpi, F., Borri-Brunetto, M., and Pallara, O.: An apparatus for in-situ direct shear tests on snow, Exp. Techniques, 37, 12046, doi:10.1111/ext.12046, 2013.

Birkeland, K. W., Kronholm, K., Logan, S., and Schweizer, J.: Field measurements of sintering after fracture of snowpack weak layers, Geophys. Res. Lett., 33, L03501, doi:10.1029/2005GL025104, 2006.

Blackford, J. R.: Sintering and microstructure of ice: a review, J. Phys. D, 40, R355-R385, doi:10.1088/0022-3727/40/21/R02, 2007.

Casassa, G., Narita, H., and Maeno, N.: Shear cell experiments of snow and ice friction, J. Appl. Phys., 69, 3745-3756, 1991.

Colbeck, S. C.: A Review of Sintering in Seasonal Snow, CRREL Report, US Army Corps of Engineers, Cold Regions Research \& Engineering Laboratory, 97-10, 1997.

de Montmollin, V.: Shear tests on snow explained by fast metamorphism, J. Glaciol., 28, 187-198, 1982.

Domine, F., Bock, J., Morin, S., and Giraud, G.: Linking the effective thermal conductivity of snow to its shear strength and density, J. Geophys. Res., 116, F04027, doi:10.1029/2011JF002000, 2011.

Fierz, C., Armstrong, R. L., Durand, Y., Etchevers, P., Greene, E., McClung, D. M., Nishimura, K., Satyawali, P. K., and Sokratov, S. A.: The International Classification for Seasonal Snow on the Ground, Tech. Doc. Hydrol., 83, UNESCO-IHP, Paris, 2009.

Fyffe, B. and Zaiser, M.: The effects of snow variability on slab avalanche release, Cold Reg. Sci. Technol., 40, 229-242, 2004.

Gallet, J.-C., Domine, F., Zender, C. S., and Picard, G.: Measurement of the specific surface area of snow using infrared reflectance in an integrating sphere at 1310 and $1550 \mathrm{~nm}$, The Cryosphere, 3, 167-182, doi:10.5194/tc-3-167-2009, 2009.

Gubler, H.: Determination of the mean number of bonds per snow grain and of the dependence of the tensile strength of snow on stereological parameters, J. Glaciol., 20, 329-341, 1978.
Gubler, H.: Strength of bonds between ice grains after short contact times, J. Glaciol., 28, 457-473, 1982.

Hagenmuller, P., Theile, T. C., and Schneebeli, M.: Numerical simulation of microstructural damage and tensile strength of snow, Geophys. Res. Lett., 41, 86-89, doi:10.1002/2013GL058078, 2013.

Heierli, J., Gumbsch, P., and Zaiser, M.: Anticrack nucleation as triggering mechanism for snow slab avalanches, Science, 321, 240-243, doi:10.1126/science.1153948, 2008.

Hobbs, P. V. and Mason, B. J.: The sintering and adhesion of ice, Philos. Mag., 9, 181-197, 1964.

Jamieson, J. B. and Johnston, C. D.: Snowpack factors associated with strength changes of buried surface hoar layers, Cold Reg. Sci. Technol., 30, 19-34, 1999.

Louchet, F.: Creep instability of the weak layer and natural slab avalanche triggerings, Cold Reg. Sci. Technol., 33, 141-146, 2001.

Louchet, F., Faillettaz, J., Daudon, D., Bédouin, N., Collet, E., Lhuissier, J., and Portal, A.-M.: Possible deviations from Griffith's criterion in shallow slabs, and consequences on slab avalanche release, Nat. Hazards Earth Syst. Sci., 2, 157-161, doi:10.5194/nhess-2-157-2002, 2002.

Maeno, N. and Ebinuma, T.: Pressure sintering of ice and its implication to the densification of snow at polar glaciers and ice sheets, J. Phys. Chem., 87, 4103-4110, doi:10.1021/j100244a023, 1983.

Matsushita, H., Matsuzawa, M., and Abe, O.: The influences of temperature and normal load on the shear strength of snow consisting of precipitation particles, Ann. Glaciol., 53, 31-38, doi:10.3189/2012AoG61A022, 2012.

Mellor, M.: A review of basic snow mechanics, Int. Assoc. of Hydrol. Sci., Geneva, Switzerland, Publ. 114, 251-291, 1975.

McClung, D. M.: Shear fracture precipitated by strain softening as a mechanism of dry slab avalanche release, J. Geophys. Res., 84 , 3519-3526, doi:10.1029/JB084iB07p03519, 1979.

McClung, D. M.: The critical size of macroscopic imperfections in dry snow slab avalanche initiation, J. Geophys. Res., 116, F03003, doi:10.1029/2010JF001866, 2011.

McClung, D. M. and Schaerer, P.: The Avalanche Handbook, 3rd Edn., Mountaineers, Seattle, Wash, 2006.

Ramseier, R. O. and Sander, G. W.: Sintering of Snow as a Function of Temperature, Symposium at Davos 1965 - Scientific Aspects of Snow and Ice Avalanches, 5-10 April 1965, Int. Assoc. of Sci. Hydrol., Geneva, Switzerland, Publ., 69, 119-127, 1966.

Reiweger, I.: Failure of Weak Snow Layers, Ph.D. thesis, ETH Zurich, Switzerland, Diss. ETH No. 19457, 2011.

Reiweger, I., Schweizer, J., Dual, J., and Herrmann, H. J.: Modelling snow failure with a fibre bundle model, J. Glaciol., 55, 997-1002, doi:10.3189/002214309790794869, 2009.

Szabo, D. and Schneebeli, M.: Subsecond sintering of ice, Appl. Phys. Lett., 90, 151916, doi:10.1063/1.2721391, 2007.

Schweizer, J.: Review of dry snow slab avalanche release, Cold Reg. Sci. Technol., 30, 43-57, 1999.

van Herwijnen, A. and Miller, D. A.: Experimental and numerical investigation of the sintering rate of snow, J. Glaciol., 59, 269274, doi:10.3189/2013JoG12J094, 2013. 